\title{
SNAPSHOT 5: CONTEMPLATIVE RUNNING
}

Daniel Plá

The first time I heard of Nicolás Núñez was during a meeting with scholars and artists at the University of Huddersfield in 2014. I was introduced to the practice of Citlalmina by Karoliina Sandström. It was a hard challenge to go through all the cycles as it is a very energetic form. So, in the summer of 2016, when finally I met Nicolás, I found myself a bit concerned about the training and about how an overweight man in his 40's like me would be able to engage in such intense activity. That was my spirit when I walked into the studio to start the workshop.

After the usual introductions, we started with running meditation. I started slowly, just a bit faster than walking. Travelling anti-clockwise, I drew my senses inward, feeling the pulsation coming from my movement, speeding up as the energy rose. In front of a me, a partner ran. The walls passed by me from time to time while I kept the rhythm, attending to my breathing and the sensations coming from the body. The first signs of tiredness started to arise, and I decided to keep running. My breathing began to get faster and shorter.

Looking to the group running with me, I started to see us as warriors, each running their own path, and I was magnetized by my partner. It was as if I was not me but the shadow of that person. After a while, my breath started to become heavy; I am not sure how long we had been running by that time. Fear started to arise, but I decided not to stop. Feeling the pulsation of my body, I noticed a place in myself where I could find rest in the middle of storm. Running became my meditation object, a source of a great variety of sensations, emotions, formations. Running was a support for my consciousness which started to become sharper. Thoughts, feelings, emotions passed in front of me, reflected on the running mirror. The more I ran, the more deeply I travelled inside myself, and the more my impulses gained space and time in the room. 
Meditative running.

Back home in Brazil, I introduced my students to this process. Running together, we discovered a way to enliven the body. Through relaxation in response to the intensity that running promotes, we found an effective tool for looking inside and for freeing impulses from the body into actions - a way to put the internal world out, into time and space. 